\title{
BMJ Open Trend of unintentional suffocation death for infants under 1 year of age from 2009 to 2018 in Hunan, China: a cross-sectional study
}

Fanjuan Kong, Aihua Wang, Jian He, Lili Xiong, Donghua Xie, Jinping Su, Zhiyu Liu (1)

To cite: Kong F, Wang A, He J, et al. Trend of unintentional suffocation death for infants under 1 year of age from 2009 to 2018 in Hunan, China: a cross-sectional study. BMJ Open 2020;10:e038666. doi:10.1136/ bmjopen-2020-038666

- Prepublication history for this paper is available online. To view these files, please visit the journal online (http://dx.doi. org/10.1136/bmjopen-2020038666).

Received 19 March 2020 Revised 12 0ctober 2020 Accepted 24 0ctober 2020

\section{Check for updates}

(c) Author(s) (or their employer(s)) 2020. Re-use permitted under CC BY-NC. No commercial re-use. See rights and permissions. Published by BMJ.

Information Management Section, Hunan Province, Changsha, Hunan, China

Correspondence to Dr Zhiyu Liu; 327532957@qq.com

\section{ABSTRACT}

Objective Few studies have addressed the unintentional suffocation of infants in China. This study is to assess the mortality rate of unintentional suffocation among infants and the differences across age groups, gender, rural versus urban locations and related healthcare services. Design A cross-sectional study on unintentional suffocation death of infants under 1 year of age in Hunan Province from 2009 to 2018.

Setting Hunan Province, with a population of 74 million, has an area of 210000 square kilometres and 123 counties/districts.

Participants The total data of 4109 unintentional suffocation deaths of infants in Hunan Province from 2009 to 2018 was collected, including 2331 boys, 1766 girls, 12 infants of unknown gender, 2906 rural children and 1203 urban children.

Main outcome measure The unintentional suffocation mortality rate of infants is defined as the number of unintentional suffocation deaths of children under 1 year of age per 100000 live births in the same year. Results The infant mortality rate showed a downward trend from 2009 to 2018. Infant unintentional suffocation death decreased first and then fluctuated. The proportion of unintentional suffocation death to infant death showed an upward trend in fluctuation. Boys and rural children had higher mortality rates than those of girls and urban children. A total of $43.5 \%$ of the deaths occurred in winter. Forty-eight per cent of the unintentional suffocations were infants between 1 and 4 months of age. A total of $46.4 \%$ of the deaths occurred at home, and $71.6 \%$ were not treated; approximately $81.8 \%$ of the untreated cases were mainly due to a lack of time to get to the hospital. A total of $65.2 \%$ of the deaths were diagnosed postmortem.

Conclusion The mortality rate of unintentional suffocation among infants in Hunan Province should attract the attention of the population, and measures should be taken according to epidemiological investigations.

\section{INTRODUCTION}

Suffocation is a public health concern both globally and in China. ${ }^{1-3}$ In the USA, ${ }^{4}$ Canada, ${ }^{5} \operatorname{Japan}^{6}$ and China, ${ }^{7}$ unintentional suffocation is the leading cause of injury death among infants under 1 year of age. It
Strengths and limitations of this study

- To ensure that our choice is representative, our sample includes all cases of unintentional suffocation of infants under 1 year of age from 2009 to 2018

- The data of this study are true and reliable, come from the National Maternal and Child Health Surveillance system.

- The diagnostic criteria of unintentional suffocation did not change, and the changing trend of unintentional suffocation was seen more clearly.

- The data of this study analysed the incidence of unintentional suffocation in infants under 1 year of age, excluding the analysis of risk factors.

has been reported ${ }^{8}$ that China accounts for $28 \%$ of the unintentional suffocation deaths among children under 1 year of age in the world. According to the Maternal and Child Health Surveillance in China, unintentional suffocation is mostly caused by hypoxia and asphyxia caused by small babies being covered by quilts, mothers turning over and accidentally crushing to death, blockage of mothers' nipples and foreign bodies in the trachea. These injury deaths, often resulting from hazards within the sleep environment, are preventable. ${ }^{9}$

At present, there are few $\operatorname{articles}^{1-3}$ on the unintentional suffocation of children in China, and most of the articles are aimed at children under the age of 5 . This is a significant research gap. We know that the incidence of unintentional suffocation in infants is much higher than that in children aged 1-4 years. Monitoring the causes and modes of unintentional suffocation in infants is essential to reducing the number of child deaths.

The China Child Development Plan (2010-2020) issued by the State Council ${ }^{10}$ recommends that the infant mortality rate be controlled at below 10 per thousand and that 
the accidental asphyxia mortality rate be reduced. Therefore, this study included a large sample size of 4109 cases and analysed the distribution of sex and urban and rural areas and explained the treatment of accidental asphyxia in China for the first time, which is an essential supplement to the study of unintentional suffocation in China.

\section{METHODS}

Mortality data were retrieved from the Maternal and Child Health Surveillance System in China. The Maternal and Child Health Surveillance System is a representative source of health information in China. Applicable data from the National Maternal and Child Health Surveillance System have been adopted by the National Bureau of Statistics, the working Committee on Women and Children of the State Council and relevant international organisations. Maternal and child health information formulates health policies for governments at all levels. In particular, maternal and child health policies provide a scientific basis. ${ }^{11}$ In 2005, a web-based online reporting system was introduced to improve the timeliness of data reporting. Because the data on the deaths of under-5 children in Hunan Province were derived from the Hunan Province Under-5 Mortality Surveillance Network. It is the second use of the data, no further ethical approval was required for the present study.

Hunan Province is located in southeastern China; it covers an area of 210000 square kilometres and has a population of 74 million, with 123 counties (districts) and 14 cities. The Maternal and Child Health Surveillance System includes all the counties and cities in Hunan Province to achieve complete population coverage.

This study included data on the unintentional suffocation deaths of all children under 1 year of age in Hunan Province from 2009 to 2018. Case surveillance data included underlying cause of death, date of death, place of death, sex, age and treatment. The cause of death was determined by trained coders from local hospitals and maternal and child health hospitals, following the International Classification of Diseases (ICD) 10th revision, and was reported to maternal and child health institutions at a higher level following the standardisation programme.

Every case of death of a child under the age of 5 shall be reported by the village doctor (community doctor) to the maternal and child doctor in the township health centre (community health service centre) within 10 days, and the maternal and child doctor in the township health centre (community health service centre) shall enter the village within 7 days to verify that if the child is not hospitalised and dies at home or on the way to medical treatment, a questionnaire survey will be conducted with the questionnaire on the death of children in non-medical institutions to infer the cause of death. Fill in the "child death report card', if a child dies in a hospital, the death diagnosis of the hospital shall prevail, fill in the "child death report card' and record it in the register of children under 5 years of age and the register of child deaths. If an autopsy is performed, it will also be recorded in the death report card. Every month, the register of child deaths in the maternal and child surveillance system should be checked with the departments of disease control, civil affairs and public security, and the data will also be improved and revised.

The data of this study are based on the China Maternal and Child Health Surveillance work Manual (2006 and 2013 editions). The time span used covers the period from 2006 to 2019. In order to facilitate international comparison, both versions of the working manual require the ICD-10 code for the fundamental deaths of children under 5 years of age in China. At the same time, considering the main causes of death of children under 5 years of age and the actual ability of grass-roots health workers to master the diagnosis and classification of children's diseases, 34 kinds of causes of death were put forward. Accidental deaths include drowning, traffic accidents, unintentional suffocation, accidental falls and other accidents (such as electrocution, smashing, hacking, biting, gunshot wounds, drowning, abandonment and so on). In this study, unintentional suffocation refers to the fact that babies are covered with quilts caused by accidental causes such as hypoxia and asphyxia, and the mother will be accidentally broken, including mother's nipple blockage and tracheal foreign bodies and so on.

Data were exported to Microsoft Excel 2010 and analysed with SPSS V.18.0. The total infant mortality rate, disease classification mortality rate, gender, urban and rural death composition and sociological characteristics were analysed by ratio and proportion.

\section{Patient and public involvement}

Patients and/or the public were not involved in the design, or conduct, or reporting, or dissemination plans of this research.

\section{RESULTS}

From 2009 to 2018, a total of 4109 cases of the unintentional suffocation of an infant ( $<1$ year) were reported in Hunan Province. The infant mortality rate showed a downward trend, from 775.6 per 100000 in 2009 to 335.5 per 100000 in 2018. Nevertheless, the mortality rate of unintentional suffocation fluctuated greatly, indicating a downward trend from 2009 to 2014 but showing a fluctuating upward trend from 2014 to 2018. It is worth noting that the proportion of unintentional suffocation in infant mortality increased between 2009 and 2018. Unintentional suffocation accounted for $15 \%$ of infant deaths in 2018, as seen in table 1 .

Throughout the study period, the unintentional suffocation mortality rate of boys and rural infants was higher than those of girls and urban infants. From 2009 to 2018, all groups followed a similar pattern in terms of unintentional suffocation mortality (table 2 ).

From spring to winter, the number of unintentional suffocation deaths was U-shaped. The minimum number 
Table 1 Infant deaths and unintentional suffocation deaths in Hunan Province, China, 2009-2018

\begin{tabular}{|c|c|c|c|c|c|c|}
\hline \multirow[b]{2}{*}{ Year } & \multirow[b]{2}{*}{$\begin{array}{l}\text { Number of live } \\
\text { births }\end{array}$} & \multicolumn{2}{|c|}{ Infant death } & \multicolumn{3}{|c|}{ Unintentional suffocation of infant } \\
\hline & & $\mathbf{N}$ & $\begin{array}{l}\text { Mortality rate (per } \\
100000 \text { persons) }\end{array}$ & $\mathbf{N}$ & $\begin{array}{l}\text { Mortality rate (per } \\
100000 \text { persons) }\end{array}$ & $\begin{array}{l}\text { Percentage of infant } \\
\text { deaths }(\%)\end{array}$ \\
\hline 2009 & 781026 & 6058 & 775.6 & 605 & 77.5 & 10.0 \\
\hline 2010 & 797902 & 5868 & 735.4 & 488 & 61.2 & 8.3 \\
\hline 2011 & 805360 & 5138 & 638.0 & 501 & 62.2 & 9.8 \\
\hline 2012 & 838974 & 4803 & 572.5 & 538 & 64.1 & 11.2 \\
\hline 2014 & 780572 & 3277 & 419.8 & 257 & 32.9 & 7.8 \\
\hline 2015 & 781066 & 3117 & 399.1 & 333 & 42.6 & 10.7 \\
\hline 2016 & 795399 & 2825 & 355.2 & 329 & 41.4 & 11.6 \\
\hline 2017 & 834955 & 2592 & 310.4 & 303 & 36.3 & 11.7 \\
\hline
\end{tabular}

of people from April to June was 541 (13.2\%), followed by $742(18.1 \%)$ from June to September, followed by 1037 (25.2\%) from January to March, and the highest was 1789 (43.5\%) from October to December. The proportion of each month-based age group was as follows: from 5 to 11 months, 800 infants, accounting for $19.5 \%$; from 1 to 4 months old, 1981 infants, accounting for $48.2 \%$ and for 0 months, 1328 infants, accounting for $32.3 \%$, as seen in figure 1 .

In this study, $56.7 \%$ of the infants were male, and $43.0 \%$ were female. A total of $91.9 \%$ were full-term babies, $97.8 \%$ were registered locally, $94.7 \%$ were born in medical institutions and $46.4 \%$ of the deaths occurred at home; $71.6 \%$ (2942) of the infants did not receive treatment after unintentional suffocation, and $81.8 \%$ (2406) of the 2942 cases did not receive treatment because it was too late to get to the hospital. The diagnosis of death was based on clinical practice $(33.4 \%)$ and postmortem inference $(65.2 \%)$, as seen in table 3 .

Table 2 Change in unintentional suffocation mortality for children under 1 year of age in Hunan Province, China, 2009-2018

\begin{tabular}{lllllll}
\hline & \multirow{2}{*}{$\begin{array}{l}\text { Mortality rate } \\
\text { (per 100000 }\end{array}$} & Sex & & & \multicolumn{2}{c}{ Location } \\
\cline { 6 - 7 } Year & persons) & Boy & Girl & & Urban & Rural \\
\hline 2009 & 77.5 & 85.6 & 68.1 & & 84.1 & 63.8 \\
\hline 2010 & 61.2 & 63.7 & 57.7 & 64.5 & 54.3 \\
\hline 2011 & 62.2 & 61.1 & 61.4 & 63.8 & 56.6 \\
\hline 2012 & 64.1 & 68.8 & 58.8 & 67.0 & 58.4 \\
\hline 2013 & 48.8 & 49.1 & 48.5 & 54.6 & 37.1 \\
\hline 2014 & 32.9 & 36.8 & 28.2 & 36.4 & 26.2 \\
\hline 2015 & 42.6 & 48.7 & 35.5 & 45.2 & 32.4 \\
\hline 2016 & 41.4 & 45.4 & 36.9 & 44.3 & 33.2 \\
\hline 2017 & 36.3 & 39.5 & 32.7 & 37.3 & 29.9 \\
\hline 2018 & 50.2 & 51.2 & 49.0 & 48.7 & 45.3 \\
\hline
\end{tabular}

\section{DISCUSSION}

To the best of our knowledge, this was the first study to examine the sociodemographic characteristics of the unintentional suffocation of infants ( $<1$ year) in a Chinese population. The main findings of our research are as follows: (1) the mortality rate of unintentional suffocation fluctuated greatly, showing a downward trend from 2009 to 2014 but a fluctuating upward trend from 2014 to 2018; (2) the unintentional suffocation mortality rate of boys and rural infants was higher than those of girls and urban infants; (3) from spring to winter, the number of unintentional suffocation deaths was U-shaped, with winter having the highest number of deaths; (4) approximately half of the infants who died were between 1 and 4 months of age, nearly half of all the infant deaths occurred at home, and most of the infants who did not receive treatment or medical treatment did so because it was too late to get to the hospital.

In this study, overall infant mortality rates declined, similar to those in the USA (2009-2015), ${ }^{12}$ Japan (2000$2009)^{6}$ and Beijing (1992-2015). ${ }^{1}$ The mortality rate of unintentional suffocation showed a downward trend from 2009 to 2014 and an upward trend from 2014 to 2018. This was different from the upward trend reported

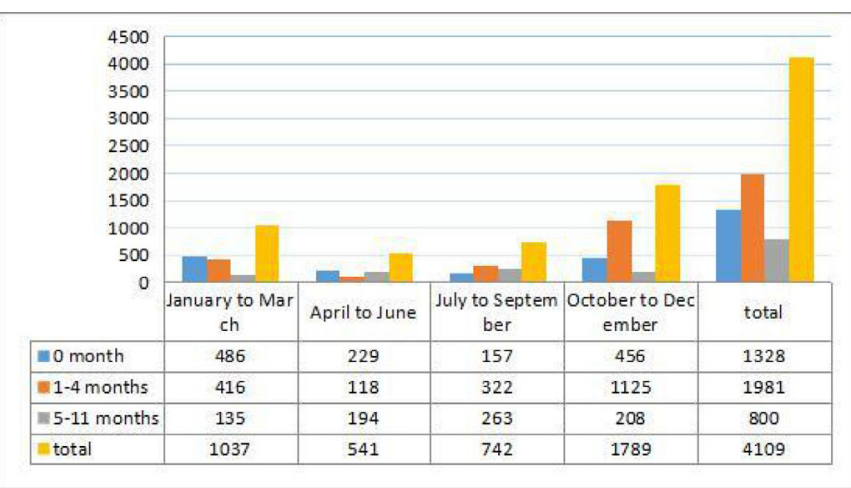

Figure 1 Unintentional suffocation death of infants of different months and quarters. 
Table 3 Basic situation of unintentional suffocation of infants from 2009 to 2018

\begin{tabular}{lrr}
\hline Items & N & $\%$ \\
\hline Infant sex & & \\
$\quad$ Boy & 2331 & 56.7 \\
Girl & 1766 & 43.0 \\
\hline Missing value & 12 & 0.3 \\
\hline $\begin{array}{l}\text { Location } \\
\text { Urban }\end{array}$ & & \\
$\quad$ Rural & 1203 & 29.3 \\
\hline
\end{tabular}

Household registration

$\begin{array}{lrr}\text { Local household registration } & 4019 & 97.8 \\ \text { Non-local domicile residence for } & 74 & 1.8\end{array}$

$<1$ year

\begin{tabular}{lrr}
$\begin{array}{l}\text { Non-local domicile residence for } \\
\text { 1 year or more }\end{array}$ & 6 & 0.2 \\
\hline $\begin{array}{lr}\text { Missing value } \\
\text { Birth place }\end{array}$ & 10 & 0.2 \\
\hline $\begin{array}{l}\text { Provincial (municipal) hospital } \\
\text { District and county hospitals }\end{array}$ & 577 & \multicolumn{1}{c}{14} \\
\hline Street (township) health centre & 1158 & 52.3 \\
\hline Village (clinic) clinic & 8 & 28.2 \\
\hline On the way & 18 & 0.2 \\
\hline Home & 145 & 3.4 \\
\hline Missing value & 55 & 1.3 \\
\hline Location of death & & \\
\hline Hospital & 867 & 21.1 \\
\hline On the way to the hospital & 499 & 12.1 \\
\hline $\begin{array}{l}\text { On the way home after hospital } \\
\text { transfer or treatment }\end{array}$ & 614 & 14.9 \\
\hline Infant's home & 1906 & 46.4 \\
\hline Missing value & 223 & 5.4 \\
\hline Die before treatment & & \\
\hline Hospitalisation & 502 & 12.2 \\
\hline Outpatient & 326 \\
\hline No treatment & 7.9 \\
\hline Missing value & 2942 & 71.6 \\
\hline
\end{tabular}

Main reasons for lack of treatment or medical treatment

\begin{tabular}{lrr}
\hline Economic difficulties & 10 & 0.3 \\
\hline Traffic inconvenience & 22 & 0.7 \\
\hline It is too late to get to the hospital & 2406 & 81.8 \\
\hline Parents do not think it is serious & 31 & 1.1 \\
\hline Customs & 6 & 0.2 \\
Others & 108 & 3.7 \\
\hline Missing value & 359 & 12.2 \\
Diagnostic basis of the cause of death & \\
\hline Pathological autopsies & 11 & 0.3 \\
\hline Clinical & 1371 & 33.4 \\
\hline
\end{tabular}

Continued
Table 3 Continued

\begin{tabular}{lrr}
\hline Items & N & \multicolumn{1}{l}{$\%$} \\
\hline Postmortem inference & 2679 & 65.2 \\
Missing value & 48 & 1.2 \\
\hline
\end{tabular}

by the USA ${ }^{12}$ from 1999 to 2015 , as well as from the downward trend reported by Japan ${ }^{3}$ and South Korea. ${ }^{14}$ The death rate of unintentional suffocation in our province in 2009-2018 (51.7/100000) was much higher than that in the USA in 1999-2002 and 2012-2015 (black, 29.03/100 000; Latino, 6.11/100000; white, 11.63/100 000). ${ }^{13}$ The occurrence of the unintentional suffocation of infants has become an upward trend, which is worthy of widespread attention.

However, a parsimonious explanation for the increase in deaths in the USA attributed to suffocation is misclassification bias arising from a change over time in the diagnosis of sudden infant death syndrome (SIDS).$^{15}$ Alternatively, the trending growth in the USA may be due to the reclassification of deaths related to states making improvements in their death scene investigation agreements that allow for the use of more accurate cause of death codes. ${ }^{12}$ The international variation of the use of ICD-10 code W75 for sleep-related deaths in infants varies widely, from $1.1 \%$ in Germany to $31.7 \%$ in New Zealand and $3.8 \%$ in England and Wales. ${ }^{16}$ In the UK, in 2014, only six infant deaths were registered under ICD-10 code W75. ${ }^{17}$ In the 'Death Monitoring Programme for Children Under 5' issued in China from 2009 to 2018, our classification of child deaths has been carried out in accordance with the ICD-10 code (W75). But unintentional suffocation, is challenging, cannot be determined by autopsy alone and may remain unresolved after a full case investigation. ${ }^{18}$ We cannot completely rule out a small number of cases of diagnosis and classification errors, but through our quality control, we try our best to control this part of the error.

Boys and rural children had higher rates of unintentional suffocation than those of girls and urban children, which was consistent with the results of studies in China, ${ }^{2}{ }^{19}$ Japan $^{20}$ and the USA. ${ }^{21}$ The lack of health education in rural areas encourages more high-risk behaviours. Economic and feasible interventions for reducing the high rates of fatal injuries in rural areas are also lacking in China. ${ }^{3}$

The rates of unintentional suffocation were higher in winter, which is consistent with Japanese reports. ${ }^{22}$ Due to long nights in cold weather, issues related to more clothing coverage,${ }^{23}$ deep sleep with pacifiers ${ }^{24}$ and quilt pressure on the child's nostrils and mouth are not found in time, resulting in accidental death. In this study, the unintentional suffocation deaths of infants aged 1-4 months accounted for nearly $50 \%$ of the cases. Studies in the $\mathrm{USA}^{9}$ have shown that $68 \%$ of the infants who die due to suffocation do so between the ages of 1 and 4 months (the median is 3 months). However, black male infants $<4$ months of age are disproportionately affected. ${ }^{25}$ 
Approximately $50 \%$ of the suffocation deaths in this study occurred at home, which is consistent with research in the USA. $^{9}$ In 2015, $79.4 \%$ of the children under the age of 5 in China who died were hospitalised before their death. ${ }^{11}$ However, the proportion of infants hospitalised before unintentional suffocation deaths in Hunan Province is only $12.2 \%$. It shows that the accessibility of these child health services and the quality of newborn health services are still poor. Parents and guardians lack first aid knowledge and do not receive enough health education information. ${ }^{26}$ Because of the sudden and unpredictable nature of accidental deaths, $81.8 \%$ of the unintentional suffocation deaths were due to a lack of time to get to the hospital for treatment. Paediatric healthcare providers should be encouraging parents and other caregivers to learn choking first aid, as well as offering anticipatory, age-appropriate guidance. ${ }^{27}$ It is essential to establish a frontline social first aid system prior to the hospital and improve and popularise the rescue abilities located at the accidental injury site, which is an important measure for reducing the rate of unintentional suffocation deaths. To increase the understanding and prevention of environmental risk factors is the basis to put an end to unintentional suffocation.

The incidence of unintentional suffocation in children $<1$ year of age was high, and the reasons are as follows: it is mainly due to the imperfect physiological functions of newborns and infants and poor care by parents, which leads to asphyxia in bedding or improper feeding, and asphyxia caused by foreign bodies in the respiratory tract. ${ }^{28}$ In China, children have the habit of sleeping in the same bed with their parents, where quilts and pillows cover the baby's mouth and nose or parents' arms and legs oppress the baby's respiratory tract at night, resulting in unintentional suffocation. ${ }^{29}$

The Academy of Breastfeeding Medicine ${ }^{30}$ and some studies $^{31}$ have shown that sharing a bed alone does not increase the risk of death. Safe sleep environments can reduce infant suffocation deaths. ${ }^{9}$ Most unexplained infant deaths are potentially preventable and occur in highly dangerous sleep environments. ${ }^{32}$ The safest place for infants to sleep is on their backs on an unshared sleep surface, such as in a crib or bassinet, in the caregivers' room, and without soft bedding (eg, blankets, pillows and other soft objects) in their sleep area. ${ }^{33}$

In the early 1990s or earlier, many high-income countries made reducing the rate of accidental injuries to children the primary goal of their health policy. After years of practice and research, the prevention of accidental injuries in children has achieved remarkable results in these countries. ${ }^{34}$ Strengthening the management of accidental injury in critical areas and populations, reducing the number of deaths caused by unintentional suffocation and paying attention to the prevention of unintentional suffocation in infancy are the keys to reducing the rate of unintentional deaths in children under 5years of age. As long as we strengthen the research on accidental asphyxia, establish an information network on accidental asphyxia, mobilise all sectors of society to care for and support the prevention of accidental asphyxia and do an excellent job regarding the safety education and propaganda given to parents and guardians, then the incidence rate of death due to accidental asphyxia in children can be reduced.

A few factors limited this study. First, the mechanical causes of suffocation were not counted, such as suffocation caused by being covered on the bed or choking on milk. Second, without gathering information on the many valuable exposure variables related to accidental asphyxia in children (eg, location, time, activity, product information related to fatal asphyxia), we cannot conduct detailed analyses to explain the recent mortality changes with confidence. To this end, the research group is actively securing research funds and will carry out the next step of the research work.

In conclusion, we report a steady decline in infant mortality under the age of 1 between 2009 and 2018 but an increase in infant accidental asphyxia mortality, especially among boys and rural children. Throughout the period studied, most of the unintentional suffocation cases occurred at home, most of them were children aged 1-4 months, and most of them did not receive treatment because of a lack of time to get to the hospital. We should pay great attention in reducing the occurrence of accidental suffocation, especially by analysing the causes of this rising trend.

Contributors FK drafted the initial manuscript, and reviewed and revised the manuscript. AW, JH, LX, DX and JS designed the data collection instruments, collected data, carried out the initial analyses and reviewed and revised the manuscript. ZL conceptualised and designed the study, coordinated and supervised data collection and critically reviewed the manuscript for important intellectual content. All authors approved the final manuscript as submitted and agreed to be accountable for all aspects of the work.

Funding The authors have not declared a specific grant for this research from any funding agency in the public, commercial or not-for-profit sectors.

Competing interests None declared.

Patient consent for publication Not required.

Ethics approval The death of children under 5 years old is a statutory report of China's maternal and child health surveillance system, which is approved by the national health administration department. Every death of a child under the age of 5 needs to be reported. In this study, all possible measures have been taken to maintain the privacy of the persons listed in the established database, including the deletion of all personal identity card numbers, names, detailed home address.

Provenance and peer review Not commissioned; externally peer reviewed.

Data availability statement Data may be obtained from a third party and are not publicly available. All data relevant to the study are included in the article. Obtaining data from the maternal and child health surveillance system requires permission from government departments, and the original data are not currently available to the public. However, relevant data analysis are released to the public every year, such as government work reports, health statistical yearbooks and other materials.

Open access This is an open access article distributed in accordance with the Creative Commons Attribution Non Commercial (CC BY-NC 4.0) license, which permits others to distribute, remix, adapt, build upon this work non-commercially, and license their derivative works on different terms, provided the original work is properly cited, appropriate credit is given, any changes made indicated, and the use is non-commercial. See: http://creativecommons.org/licenses/by-nc/4.0/.

ORCID iD

Zhiyu Liu http://orcid.org/0000-0001-6534-3408

\section{REFERENCES}

1 Cao H, Wang J, Li Y, et al. Trend analysis of mortality rates and causes of death in children under 5 years old in Beijing, China from 1992 to 2015 and forecast of mortality into the future: an entire population-based epidemiological study. BMJ Open 2017;7:e015941. 
2 Lili X, Jian H, Liping L, et al. Epidemiology of injury-related death in children under 5 years of age in Hunan Province, China, 2009-2014. PLoS One 2017;12:e0168524.

3 Wang L, Gao Y, Yin P, et al. Under-five mortality from unintentional suffocation in China, 2006-2016. J Glob Health 2019;9:010602.

4 National Center for Health Statistics, National Vital Statistics System. 10 leading causes of injury deaths by age group highlighting unintentional injury deaths, United States - 2015, 2015. Available: https://www.cdc.gov/injury/wisqars/pdf/leading_causes_of_injury deaths_highlighting_unintentional_injury_2015-a.pdf [Accessed 18 Jan 2018].

5 Yao X, Skinner R, McFaull S, et al. At-a-glance - 2015 injury deaths in Canada. Health Promot Chronic Dis Prev Can 2019;39:225-31.

6 Sekii H, Ohtsu T, Shirasawa T, et al. Childhood mortality due to unintentional injuries in Japan, 2000-2009. Int J Environ Res Public Health 2013;10:528-40.

7 China maternal and child health development report, 2019. Available: HTTP://www.nhc.gov.cn/fys/s7901/201905/bbd8e2134a7e47958c5c 9ef032e1dfa2.shtm

8 Institute for health metrics and evaluation (IHME), University of Washington. GBD compare data visualization. Seattle, WA, 2016. HTTP:// vizhub.healthdata.org/gbd-compare

9 Erck Lambert AB, Parks SE, Cottengim C, et al. Sleep-related infant suffocation deaths attributable to soft bedding, overlay, and wedging. Pediatrics 2019;143:e20183408.

10 The State Council of the People's Republic of China. Children development compendium in China (2011-2020), 2011. Available: http://www.gov.cn/gongbao/content/2011/content_1927200.htm [Accessed 25 Sep 2017].

11 Xi J, Rong L, Bin C, et al. Survival and development strategy of $0-6$-year-old children in China-from evidence to action. Beijing: Peking University Medical Press, 2018.

12 Gao Y, Schwebel DC, Hu G. Infant mortality due to unintentional suffocation among infants younger than 1 year in the United States, 1999-2015. JAMA Pediatr 2018;172:388-90.

13 Khan SQ, Berrington de Gonzalez A, Best AF, et al. Infant and youth mortality trends by Race/Ethnicity and cause of death in the United States. JAMA Pediatr 2018;172:e183317.

14 Hong J, Lee WK, Park H. Change in causes of injury-related deaths in South Korea, 1996-2006. J Epidemiol 2011;21:500-6.

15 Womack LS, Pinckard JK, Shapiro-Mendoza CK. Measuring trends in infant mortality due to unintentional suffocation. JAMA Pediatr 2018;172:887.

16 Taylor BJ, Garstang J, Engelberts A, et al. International comparison of sudden unexpected death in infancy rates using a newly proposed set of cause-of-death codes. Arch Dis Child 2015;100:1018-23.

17 Office for National Statistics. Mortality statistics: deaths registered in England and Wales (series DR), 2014. London: UK Statistics Authority, 2015.
18 Moon RY, Task force on sudden infant death syndrome. SIDS and other sleep-related infant deaths: evidence base for 2016 updated recommendations for a safe infant sleeping environment. Pediatrics 2016;138:e20162940.

$19 \mathrm{Hu} \mathrm{G}$, Baker SP, Baker TD. Urban-rural disparities in injury mortality in China, 2006. J Rural Health 2010;26:73-7.

20 Sekii H, Ohtsu T, Shirasawa T, et al. Childhood mortality due to unintentional injuries in Japan, 2000-2009. Int J Environ Res Public Health 2013;10:528-40.

21 Mack KA, Gilchrist J, Ballesteros MF. Unintentional injuries among infants age 0-12 months. J Safety Res 2007;38:609-12.

22 Shinsugi C, Stickley A, Konishi S, et al. Seasonality of child and adolescent injury mortality in Japan, 2000-2010. Environ Health Prev Med 2015;20:36-43.

23 Zhang P, Chen R, Deng J, et al. [A prospective study on accidental deaths among 0-14-year-old children in Jiangsu, 1994-1995. Zhonghua Liu Xing Bing Xue Za Zhi 1998;19:290-3.

24 Zhang YT, BB N, BJ G, et al. Analysis and suggestions on the quality and safety of pacifiers for infants and young children. Chinese Standard 2018;1:166-8.

25 Shapiro-Mendoza CK, Kimball M, Tomashek KM, et al. Us infant mortality trends attributable to accidental suffocation and strangulation in bed from 1984 through 2004: are rates increasing? Pediatrics 2009;123:533-9.

26 Volpe LE, Ball HL. Infant sleep-related deaths: why do parents take risks? Arch Dis Child 2015;100:603-4.

27 Cyr C, Canadian Paediatric Society, Injury Prevention Committee. Preventing choking and suffocation in children. Paediatr Child Health 2012;17:91-2.

28 Blair PS, Ball HL, McKenna JJ, et al. Bedsharing and breastfeeding: the academy of breastfeeding medicine protocol \#6, Revision 2019. Breastfeeding Medicine 2020;15:5-16.

29 Blabey MH, Gessner BD. Infant bed-sharing practices and associated risk factors among births and infant deaths in Alaska. Public Health Rep 2009;124:527-34.

30 Xiuling S, Ma Wenjun XY, et al. Analysis on the characteristics of injury death of Children aged $0 \sim 14$ years in Guangdong Province from 2004 to 2005. South China J Prev Med 2014;40:180-3.

$31 \mathrm{Jh} \mathrm{L}, \mathrm{Gw}$ H. Mortality rate and causes of death among children below 5 years old in Hunan Province, 2009-2014. Pract Prev Med 2016;1:72-5.

32 Garstang J, Ellis C, Griffiths F, et al. Unintentional asphyxia, SIDS and medically explained deaths: a descriptive study of outcomes of child death review (CDR) investigations following sudden unexpected death in infancy. Forensic Sci Med Pathol 2016;12:407-15.

33 Task Force on Sudden Infant Death Syndrome. SIDS and other sleep-related infant deaths: updated 2016 recommendations for a safe infant sleeping environment. Pediatrics 2016;138:e20162938.

34 Stella K, Ep P. Oral health promotion: an essential element of a health-promoting school. Geneva: WHO, 2003. 